\title{
Senior Editor's Note: Academics Dancing
}

\author{
FINTAN WALSH
}

All issues are special, but some more purposefully so. This one has developed over years of dialogue with and between the Choreography and Corporeality and Music Theatre working groups within the International Federation for Theatre Research. Working groups are at the heart of the organization's activities, providing opportunities for scholarly engagement across topics, countries, generations and periods of time. Frequently this happens by responding to papers and performances as part of the annual conference, or during interim events, and of course via publication too. In more socially proximate times, these interactions also take the form of impromptu conversations across the day trips, dinner tables and cultural events that comprise the most rewarding conference schedules. Though many associate research with the stillness of solitary library work, most of us know it also includes the very particular commotion of academics dining and dancing at conferences.

When I think of the bodily soundscapes that guided this special issue, the tip-tapping of laptop keys first comes to mind. But when I recall all the in-person conferences and meetings that laid the groundwork for the publication, I hear ideas being shared and debated in different accents and languages; the rush of bodies into plenary halls and dining rooms; the unique hum of local streets, traffic and music. These background noises rarely rise to the surface of this issue, or any other; softened, as they tend to be, by the regulation of scholarly tone and focus. But while engaging with this issue's wide-ranging investigation into the relationship between sound and bodily movement in theatre and performance, readers might try also to tune in to the forms and frequencies of exchange, sociality and friendship that make this academic work even possible - all that we do apart, sharing pages and screens, and all that we can only do by sounding and moving in the same place. 